\title{
Spontaneous disappearance of cerebral convexity arachnoid cyst
}

Desaparecimento espontâneo de cisto de aracnoide da convexidade cerebral Hamilton Matushita ${ }^{1}$, Daniel D Cardeal², Bernardo Monaco ${ }^{3}$

Pediatric Neurosurgery Unit - Division of Neurosurgery, Hospital das Clínicas, University of São Paulo Medical School, São Paulo SP, Brazil. 1 Professor Livre-Docente at São Paulo University Medical School, São Paulo SP, Brazil;

${ }^{2}$ Medical Doctor - Staff of Pediatric Neurosurgery - Hospital das Clínicas of São Paulo University Medical School, São Paulo SP, Brazil; ${ }^{3}$ Resident of Neurosurgery - Hospital das Clínicas of São Paulo University Medical School, São Paulo SP, Brazil.

Correspondence: Hamilton Matushita; Rua Barata Ribeiro 237 / cj. 43/44/46;01308-000 São Paulo SP - Brasil; E-mail: matushita@uol.com.br Conflict of interest: There is no conflict of interest to declare.

Received 17 January 2012; Received in final form 27 January 2012; Accepted 3 February 2012

Arachnoid cysts (ACs) are congenital malformations of the arachnoid membranes and they can be located at any place along the craniospinal axis. Spontaneous disappearance of ACs is a rare, but known event. It has been reported mainly in the pediatric or adolescent periods.

\section{CASE}

An eight-year-old previously healthy boy fell off a swing in a playground and hit his head on the ground, on August 24, 2006, when he was five years-old. He presented vomiting but no disturbance of consciousness. He was admitted to the emergency unit of the hospital on the same day. Cranial computed tomography (CT) was then performed, which demonstrated an AC in the right frontal convexity, with compression and distortion of the frontal lobe, and bulging of adjacent bone, thereby causing cranial asymmetry (Fig 1A). There was no evidence of any intracranial hemorrhage related to the trauma. There were no neurological deficits. The child was discharged from the emergency unit and referred to the outpatient clinic. Magnetic resonance imaging (MRI) obtained 40 days later confirmed the previous CT findings (Fig 1B and C). The child underwent follow-up in the outpatient clinics. He remained asymptomatic and without neurological manifestations. A routine follow-up MRI, performed on July 15, 2008, revealed that the AC had completely regressed (Fig 2).

\section{DISCUSSION}

Although few cases of spontaneous disappearance of ACs have been reported in the literature, such occurrences are likely to be more common than the number of reports would suggest, because many ACs are asymptomatic and they are incidentally diagnosed, as in the present case. The

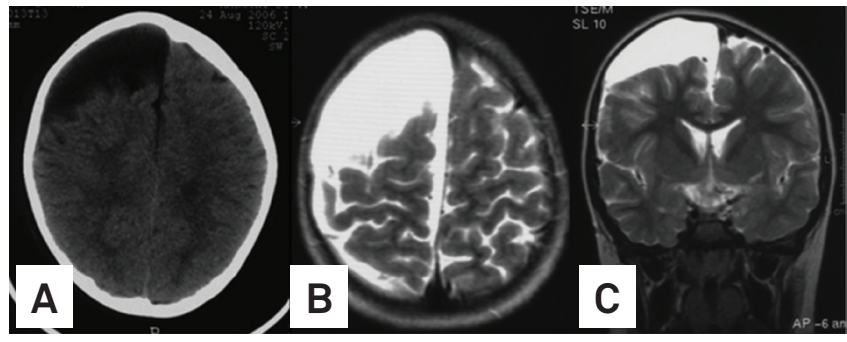

Fig 1. (A) Computed tomography (August 24, 2006) revealing a large arachnoid cyst (AC) in the right frontal convexity, associated with asymmetry of the skull; (B) axial and (C) coronal T2 - weighted magnetic resonance imaging (October 3 , 2006), showing the frontal convexity AC extending to the interhemispheric fissure.

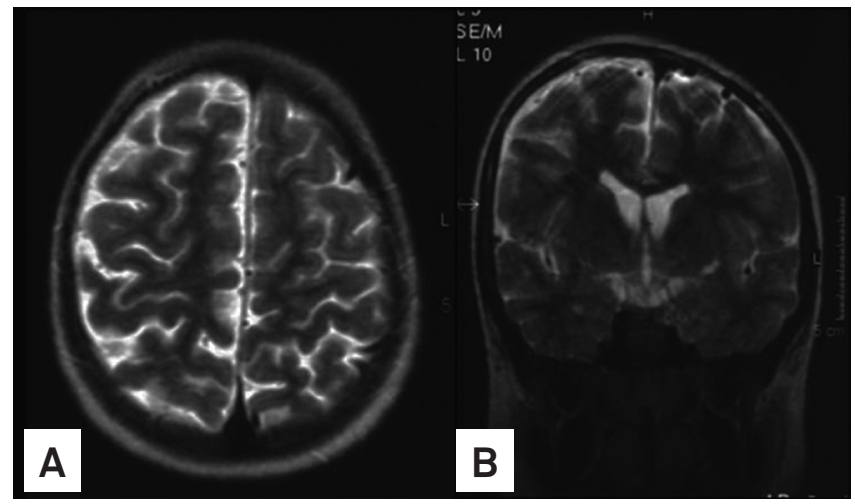

Fig 2. Follow-up magnetic resonance imaging (MRI) performed 22 months after the diagnosis. (A) Axial and (B) coronal T2weighted MRI, demonstrating disappearance of the right frontal convexity arachnoid cyst.

prevalence rate for ACs in children undergoing MRI ranges from 0.1 to $2.6 \%^{1}$. Follow-ups on patients subjected to MRI evaluations have shown that $11 \%$ of diagnosed ACs undergo reductions in size ${ }^{2}$. Resolution of ACs may either occur spontaneously or be triggered by certain events. Among the triggering events that have been correlated with regression of ACs, head injury and infection account for $38.8 \%{ }^{2}$. Previous 
infection has been postulated as an event that might lead to the disappearance of ACs, through a process of adhesion of two membranes of the cyst caused by healing. Hypotheses relating to spontaneous regression of ACs have focused primarily on occurrences of communication between the cyst and normal cerebrospinal fluid pathways ${ }^{3-5}$. Yamauchi, Saeki and Yamaura ${ }^{5}$ elaborated an interesting theory explaining the regression of the cyst, based on volumetric evaluation of the cyst. These authors observed that the volume of large cysts tends to have natural fluctuation, and they have also proposed that when the intracystic tension is high, it may spontaneously rupture, pointing out some accelerating factors, such as extreme holding of the breath, crying or Valsalva maneuver.

The possibility of spontaneous disappearance of ACs may corroborate the use of conservative therapy, especially for incidental findings of ACs. Prophylactic surgery on asymptomatic ACs is not justified, because the course with spontaneous regression has been increasingly reported in the literature. Since asymptomatic ACs may not be diagnosed, the actual rate of spontaneous disappearance of ACs may be higher than it is suggested by the literature.

\section{References}

1. Al-Holou WN, Yew AY, Boomsaad ZE, Garton HJ, Muraszko KM, Maher CO. Prevalence and natural history of arachnoid cysts in children. J Neurosurg Pediatr 2010;5:578-585.

2. Seizeur R, Forlodou P, Coustans M, Dam-Hieu P. Spontaneous resolution of arachnoid cysts: review and features of an unusual case. Acta Neurochir (Wien) 2007;149:75-78.

3. Thomas BP, Pearson MM, Wushensky CA. Active spontaneous decompression of a suprasellar pre-pontine arachnoid cyst detected with routine magnetic resonance imaging. Case report. J Neurosurg Pediatr 2009;3:70-72.

4. Hamada H, Hayashi N, Umemura K, Kurosaki K, Endo S. Middle cranial fossa arachnoid cyst presenting with subdural effusion and endoscopic detection of tear of the cyst. Neurol Med Chir (Tokyo) 2010;50:512-514.

5. Yamauchi T, Saeki N, Yamaura A. Spontaneous disappearence of temporo-frontal arachnoid cysts in a child. Acta Neurochir (Wien) 1999;141:537-540. 